REPORT SD-TR-88-60

NASA-TM-101137

19880014428

\title{
EnviroNET: An Interactive Space-Environment Information Resource
}

\author{
A. L. VAMPOLA \\ Space Sciences Laboratory \\ The Aerospace Corporation \\ El Segundo, CA 90245 \\ W. N. HALL \\ Air Force Geophysics Laboratory \\ Bedford, MA 01731 \\ M. LAURIENTE \\ NASA Goddard Space Flight Center \\ Greenbelt, MD 20771
}

24 May 1988

Prepared for

AIR FORCE GEOPHYSICS LABORATORY

Hanscom AFB, MA 01731

SPACE DIVISION

AIR FORCE SYSTEMS COMMAND

Los Angeles Air Force Base

P.O. Box 92960, Worldway Postal Center

Los Angeles, CA 90009-2960

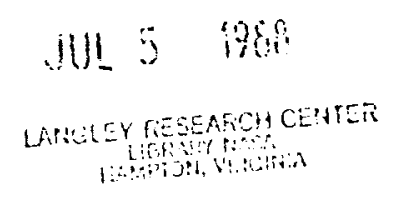

APPROVED FOR PUBLIC RELEASE;

DISTRIBUTION UNLIMITED 
This report was submitted by The Aerospace Corporation, El Segundo, CA 90245, under Contract No. F04701-85-C-0086-P00019 with the Space Division, P.0. Box 92960, Worldway Postal Center, Los Angeles, CA 90009-2960. It was reviewed and approved for The Aerospace Corporation by H. R. Rugge, Director, Space Sciences Laboratory. Lt Clarence $V$. Wilcox was the project officer.

This report has been reviewed by the Public Affairs Office (PAS) and is releasable to the National Technical Information Service (NTIS). At NTIS, it will be available to the general public, including foreign nationals.

This technical report has been reviewed and is approved for publication. Publication of this report does not constitute Air Force approval of the report's findings or conclusions. It is published only for the exchange and stimulation of ideas.

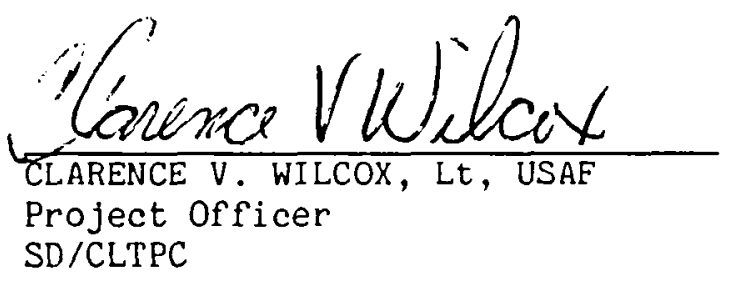

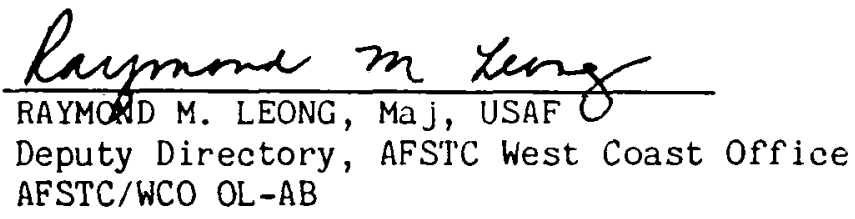




\section{REPORT DOCUMENTATION PAGE}

\begin{tabular}{|c|c|c|c|c|}
\hline \multicolumn{2}{|l|}{$\begin{array}{l}\text { 1a. REPORT SECURITY CLASSIFICATION } \\
\text { Unclassified }\end{array}$} & \multicolumn{3}{|l|}{ 16. RESTRICTIVE MARKINGS } \\
\hline \multicolumn{2}{|l|}{ 2a. SECURITY CLASSIFICATION AUTHORITY } & \multicolumn{3}{|c|}{$\begin{array}{l}\text { 3. DISTRIBUTION/AVALABILITY OF REPORT } \\
\text { Approved for public release; } \\
\text { distribution unlimited. }\end{array}$} \\
\hline \multicolumn{2}{|c|}{$\begin{array}{l}\text { 4. PERFORMING ORGANIZATION REPORT NUMBER(S) } \\
\text { TR-0088(3671-01)-1 }\end{array}$} & \multicolumn{3}{|c|}{$\begin{array}{l}\text { 5. MONITORING ORGANIZATION REPORT NUMBER(S) } \\
\text { SD-TR- } 88-60\end{array}$} \\
\hline $\begin{array}{l}\text { 6a. NAME OF PERFORMING ORGANIZATION } \\
\text { The AErospace Corporation } \\
\text { Laboratory Operations }\end{array}$ & $\begin{array}{l}\text { 6b. OFFICE SYMBOL } \\
\text { (If applicable) }\end{array}$ & \multicolumn{3}{|c|}{$\begin{array}{l}\text { 7a. NAME OF MONITORING ORGANIZATION } \\
\text { Space Division }\end{array}$} \\
\hline \multicolumn{2}{|l|}{$\begin{array}{l}\text { 6c. ADDRESS (City, State, and ZIP Code) } \\
\text { El Segundo, CA } 90245\end{array}$} & \multicolumn{3}{|c|}{$\begin{array}{l}\text { 7b. ADORESS (City, State, and ZIP Code) } \\
\text { Los Angeles Air Force Base } \\
\text { Los Angeles, CA } 90009-2960\end{array}$} \\
\hline $\begin{array}{l}\text { 8a. NAME OF FUNDING/SPONSORING } \\
\text { ORGANIZATION } \\
\text { Air Force Geophysics Laborat }\end{array}$ & $\begin{array}{l}\text { 8b. OFFICE SYMBOL } \\
\text { (If applicable) }\end{array}$ & \multicolumn{3}{|c|}{$\begin{array}{l}\text { 9. PROCUREMENT INSTRUMENT IDENTIFICATION NUMBER } \\
\text { F04701-85-C-0086-P00019 }\end{array}$} \\
\hline \multirow{2}{*}{\multicolumn{2}{|c|}{$\begin{array}{l}\text { 8c. ADDRESS (City, State, and ZIP Code) } \\
\text { Hanscom AEB, MA } 01731\end{array}$}} & \multicolumn{3}{|c|}{ 10. SOURCE OF FUNOING NUMBERS } \\
\hline & & \begin{tabular}{|l|l|} 
PROGRAM & PROJECT \\
ELEMENT NO. & NO.
\end{tabular} & $\begin{array}{l}\text { TASK } \\
\text { NO. }\end{array}$ & $\begin{array}{l}\text { WORK UNIT } \\
\text { ACCESSION NO. }\end{array}$ \\
\hline \multicolumn{5}{|c|}{$\begin{array}{l}\text { 11. TiTLE (lnclude Security Classification) } \\
\text { EnvirolNET: An Interactive Space-Environment Information Resource }\end{array}$} \\
\hline \multicolumn{5}{|c|}{$\begin{array}{l}\text { 12. PERSONAL AUTHOR(S) Vampola, Alfred L. (The Aerospace Corporation); Hall, William N. (Air } \\
\text { Force Geophysics Laboratory); Lauriente, Michael (NASA Goddard Space Flight Center) }\end{array}$} \\
\hline 13a. TYPE OF REPORT & $\begin{array}{l}\text { 13b. TIME COVEREO } \\
\text { FROM TO }\end{array}$ & \multicolumn{2}{|c|}{19 1980' MQFY REPORT (Year, Month, Day) } & COUNT \\
\hline
\end{tabular}

\begin{tabular}{|c|c|c|}
\hline 17. & \multicolumn{2}{|c|}{ COSATI COOES } \\
\hline FIELD & GROUP & SUB-GROUP \\
\hline & & \\
\hline & & \\
\hline
\end{tabular}

18. SUBJECT TERMS (Continue on reverse if necessary and identify by block number) Environment Shuttle Environment EnviroNET Space Environment

\section{ABSTRACT (Continue on reverse if necessary and identify by block number)}

EnviroNET is an interactive menu-driven system set up as an information resource for experimenters, program managers, and design and test engineers who are involved in space missions. Its basic use is as a fundamental single-source of data for the environment encountered by Shuttle and Space Station payloads, but it also has wider applicability in that it includes information on environments encountered by other satellites in both low altitude and high altitude (including geosynchronous) orbits. It incorporates both a text-retrieval mode and an interactive modeling code mode. The system is maintained on the ENVNET MicrovaX computer at NASA/Goddard Space Flight Center. Its services are available at no cost to any user who has access to a terminal and a dial-up port. It is a tail-node on SPAN, and so it is accessible either directly or through BITNET, ARPANET, and GTE/TELENET via NPSS.

\begin{tabular}{|c|c|c|c|}
\hline $\begin{array}{l}\text { 20. DISTRIBUTION /AVAILABILITY OF ABSTRACT } \\
\text { WUNCLASSIFIEDIUNLIMITED } \square \text { SAME AS RPT. }\end{array}$ & $\square$ DTIC USERS & $\begin{array}{l}\text { 21. ABSTRACT SECURITY CLASSIFICAT } \\
\text { Unclassified }\end{array}$ & ION \\
\hline 22a. NAME OF RESPONSIBLE INDIVIDUAL & & 22b. TELEPHONE (Include Area Code) & 22C. OFFICE SYMBOL \\
\hline
\end{tabular}
DD FORM 1473,84 MAR edition may be used until exhausted.
All other editions are obsolete.
SECURITY CLASSIFICATION OF THIS PAGE UNCLASSIFIED 
, 


\section{PREFACE}

We wish to thank D. Bilitra, J. Green, A. Hedin, and J. Vette of NASA/ Goddard Space Flight Center and $\mathrm{N}$. Thomson of the University of Chicago for the various modeling codes used in EnviroNET. Funding was provided by NASA Headquarters, the AFGL Space Systems Environmental Interactions Technology Office, and by the U.S. Air Force Systems Command's Space Division under Contract No. F04701-85-C-0086-P00019. 
• 
INTRODUCTION

The extensive use of space for platforms for communications, surveillance such as weather and earth resources, science research, military objectives, and manned activities is continuing to increase. With this increase comes an equivalent increase in the number of personnel who have to have knowledge about or access to information about the space environment and the local environment encountered on space platforms such as Shuttle or Space Station. Initially, many of these individuals do not have the appropriate technical background to be familiar with sources for the space environment data they require. There is also a need for a focal point of such information so that groups working on the same mission at different institutions have a common data base for use in their respective portions of the mission. Additionally, the common source should be easily modified and maintained with the most recent data available. EnviroNET has been created to perform this role.

\section{DESCRIPTION}

EnviroNET is an information resource for experimenters, design and test engineers, and program managers who are involved with space missions. Its basic use is as a fundamental single repository of information about the environmental areas of concern encountered by Shuttle and Space Station payloads, but it also has wider applicability for information on the somewhat hostile space environments encountered by satellites in both low altitude and high (including geosynchronous) orbits. It is maintained by NASA through cooperative efforts of industry, other government agencies, academia, and the NASA community.

EnviroNET incorporates a combination of expository text and numerical tables amounting to about one million characters (bytes) plus FORTRAN programs that model the neutral atmosphere, ionosphere, geomagnetic field, and the energetic electron and proton environments. This text is under continuous review, correction, and augmentation by ten subpanels of technical experts -- 
one for each of the main topics dealt with. The aim is to keep it as accurate and current as possible. The EnviroNET files are stored on a MicrovaX II computer at Goddard Space Flight Center and may be accessed on a 24-hour dialup basis at 300/1200 baud with ordinary telephone connections and at 9600 baud for users on the Space Physics Analysis Network (SPAN). The SPAN network includes several hundred computers in the U.S. and in other countries.

EnviroNET is ideally suited for the science users who find it desirable and feasible to perform an increasing amount of their work by computer networking with their colleagues from their "remote" home laboratories and computers. This is an expansion of the concept started with the Atmosphere Explorer and Dynamics Explorer programs wherein remote scientists were connected over dedicated phone lines to a central "remote" computer site containing their data and computer programs. With the advent of SPAN, the remote Dynamics Explorer scientists could communicate with one another directly and offload calculations and data analysis to their home systems, thereby improving productivity with simultaneous analysis on remote, distributed computer systems. Following this example, we are creating a facility to permit the user to conduct teleanalysis, i.e., perform analysis of the Space Shuttle/ Space Station environment data and use the space environment models on computers at remote institutions. This effort will include the NASA centers, other government laboratories, industry, and universities.

The academic community is also involved because it provides important opportunities for testing and evaluating new ideas, techniques and concepts before they have reached the state of maturity considered by contractors and project managers as being suitable for implementation. This testbed program provides a valuable way of training the graduate students who represent the future scientists and engineers of the nation, and who need to be at the leading edge of our developing technology to ensure our economic survival.

The various facilities in EnviroNET are accessed by a menu-driven system which includes a number of options: Retrieval and reading or downloading of text; summaries and/or plots of environmental parameters; on-line computations of magnetic field parameters, particle fluxes, atmospheric constituents, etc. For more detailed studies, software can be downloaded to the user's computer for use at his/her facility. 
When the system is accessed for information, the Table of Contents is displayed and the user is instructed to select a topic. When the user has finished his/her activities related to the selected topic, the user is returned to the Table of Contents for additional topic selections. The menudriven system includes the following options:

- retrieval and reading or downloading of text;

- downloading of high-resolution graphics summaries and/or environmental parameters;

- on-line computations of magnetic field parameters;

- on-line computations of particle fluxes, atmospheric constituents, etc.

Data flow in the EnviroNeT system is shown in Figure 1. Text, data, and environmental models reside in a number of files on the ENVNET computer. A number of modeling groups, including the Natural Environments group with which we are associated, are responsible for the text, data bases, models, and interactive computation programs. These modules are installed and maintained on the EnviroNET system by NASA personnel who work directly on the ENVNET computer.

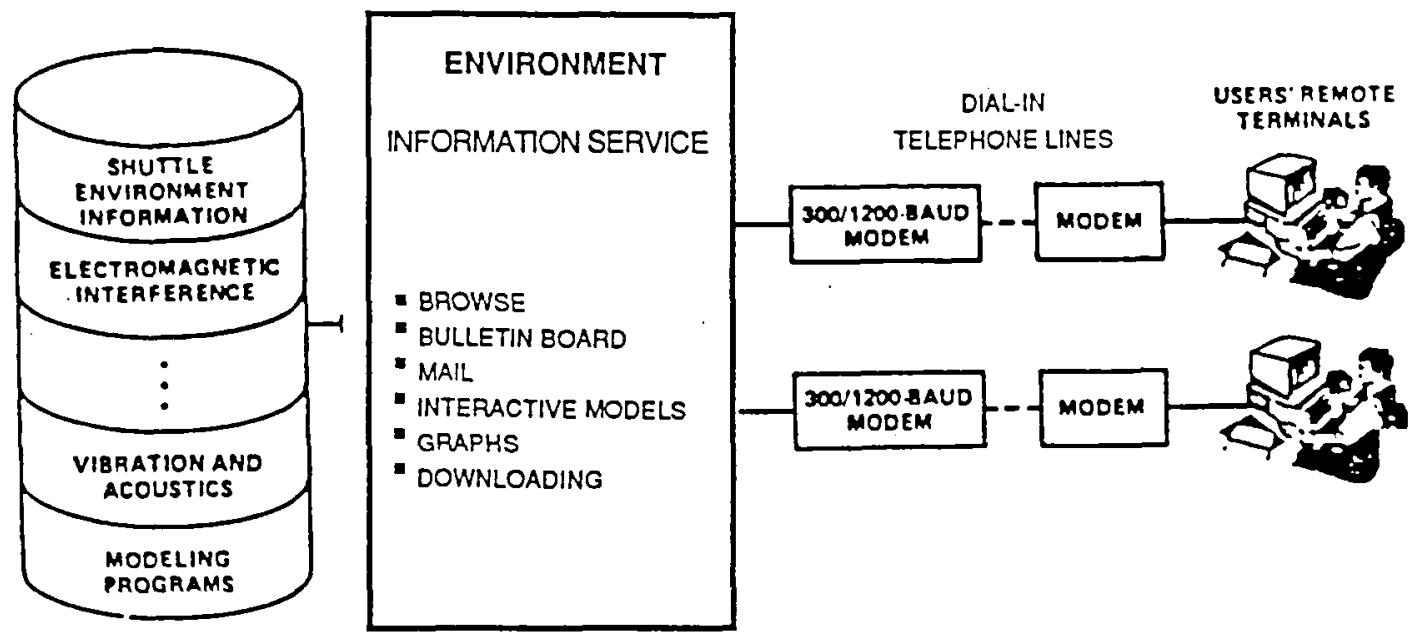

Figure 1. Data Flow in EnviroNET 
User access to EnviroNET is shown in Figure 2. EnviroNET is a tail node on SPAN. Thus anyone who has access to SPAN either directly or through BITNET or ARPANET can access EnvirONET simply (e.g., using the SET HOST feature). Those who do not have access to SPAN directly can get access through the local GTE/TELENET system. To do this, they must obtain the GTE/TELENET local phone access number and enter through NPSS. Details for this access are available from NASA/Goddard. No charge is made for accessing and using EnviroNET, but users should avoid overloading or otherwise abusing the system. Rather than reading through many pages of text on-line, the text should be down-loaded to the user's local system and accessed there.

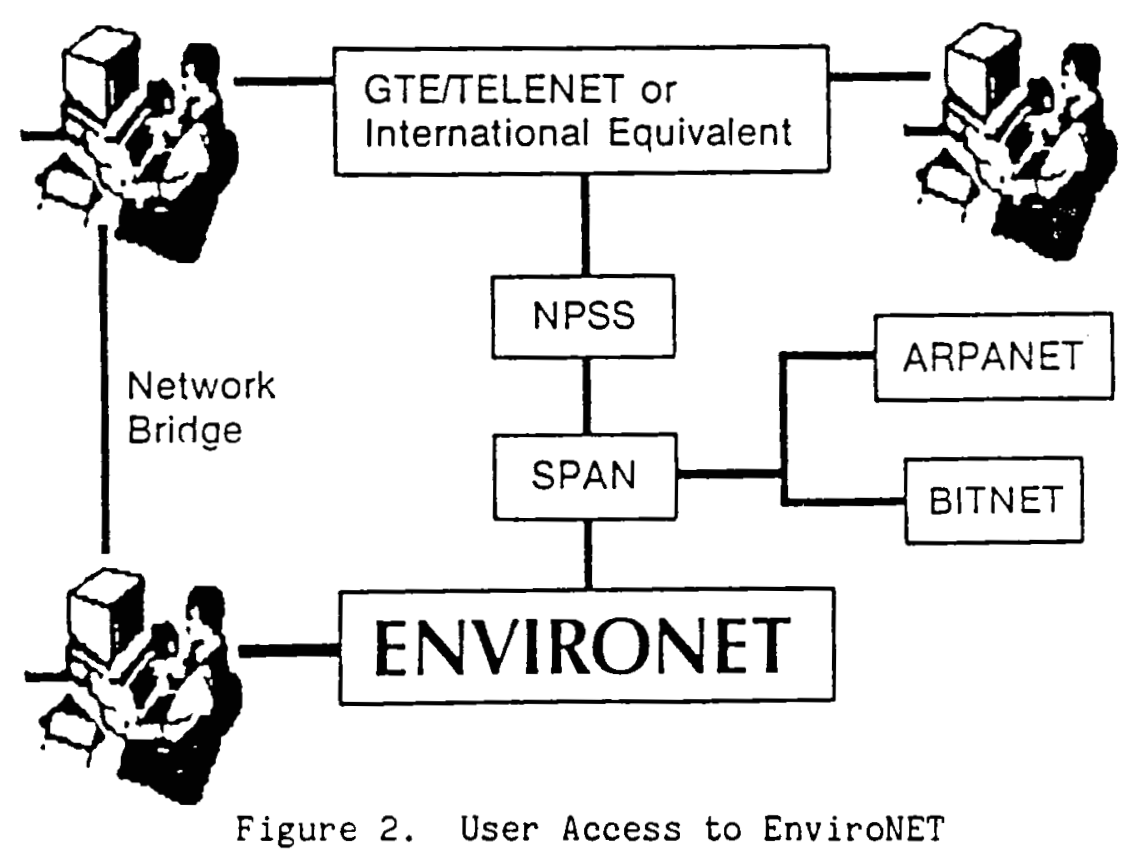

BROWSE

For an introduction to the system (or for very short inquiries), the BROWSE system is available. The BROWSE system is menu-driven and permits fast, easy access to specific information in the system. It permits a number of activities: 
- display of main topic headings;

- display of index of key-words and topics with chapter and page numbers;

- direct access to any specified page, plus forward and backward paging through text;

- search of indexed key-words or phrases;

- search of any character string in text.

For more detailed studies, text and software files can be downloaded to the user's computer for use at his/her facility.

DOWNLOADING TEXT AND FIGURES

Text may be downloaded by a number of options: KERMIT; direct copy to the screen with capture software at the user's end; or, by using the DEC file transfer protocols available on SPAN. Note that if the text is downloaded by copying it to the screen, it is up to the user to capture it on the local computer as it is displayed. The DEC file transfer method is much faster and can be done in batch mode, provided your terminal has access to SPAN. The chapters which may be downloaded as text are the following:

Thermal and Humidity

Vibration and Acoustics

Electromagnetic Interference

Loads and Low Frequency Dynamics

Microbial and Toxic Contaminants

Molecular Contamination

Natural Environment

Orbiter Motion

Particulate Environment

Surface Interactions

Definitions and Acronyms 
The technical content of the information is constantly improved to keep it current. After flight data have been extracted, analyzed, and verified by other scientists, the information is entered into EnviroNET. The inclusion of models makes EnviroNET an interactive system instead of just an archive of information. Panels are contributing new information on a continuing basis. They are also trying to work with principal investigators on extraction of flight data from experiments and are participating in technical meetings and workshops.

Data graphs and figures can be downloaded as bitmaps from EnviroNET for viewing on a user's terminal if a color board and a color monitor are available. The KERMIT protocol is used. First, the graphics software is downloaded; then the figure is selected and may be downloaded either using KERMIT or by a direct copy to the user's terminal using the DEC file transfer protocols.

\section{INTERACTIVE SOFTWARE AND MODELS}

The current interactive computation software includes a magnetic field tracing routine, several energetic particle models, MSIS-86, and the International Reference Ionosphere. The models are accessed by entering the Function Calculation System selected from the main menu. When this system is selected, a new menu is displayed from which one can select the MSIS- 86 Neutral Thermosphere Model, the International Reference lonosphere, the Magnetic Field Model, or Energetic Particles Models. A brief description of each of these follows.

The MSIS-86 Neutral Thermosphere Model is the 1986 COSPAR International Reference Atmosphere and is based on in-situ composition and temperature measurements and ground-based radar measurements covering a complete solar cycle. The inputs required, which are prompted for, are: day, altitude, latitude, longitude, local time, $F_{10.7}$ flux (both 3 -month and previous day averages), and the magnetic index $A_{p}$. The model, which is valid over the altitude range of $85 \mathrm{~km}$ to $1000 \mathrm{~km}$, produces the following outputs: number densities of $\mathrm{H}, \mathrm{N}, \mathrm{He}, \mathrm{N}_{2}, \mathrm{O}_{2}$, and $\mathrm{Ar}$ in $\mathrm{cm}^{-3}$, total mass density in $\mathrm{gm} / \mathrm{cm}^{3}$, and exospheric temperature and the temperature at the selected altitude, both in $\mathrm{o}_{\mathrm{K}}$. 
The International Reference Ionosphere Model (IRI-86) provides the ionospheric density and temperature, electron density profiles, electron and ion temperatures, ion composition $\left(\mathrm{O}_{+}, \mathrm{H}+, \mathrm{He}+, \mathrm{O}_{2}^{+}\right.$, and $\left.\mathrm{NO}_{+}\right)$and a 12-month running mean sunspot number. Again, temperatures are in ${ }^{\circ} \mathrm{K}$ and compositions are in $\mathrm{cm}^{-3}$. The model prompts for geographic latitude, longitude, altitude, month, local time, and solar activity (quiet, moderate, or active).

The Magnetic Field Model used is a much-modified version of a code originally written by G. Mead. For the internal field, the model permits the user to select a dipole field or any of the standard internal field coefficient sets: the Definitive Geomagnetic Reference Fields (DGRF) for 1965, 1970, 1975, and 1980 and the International Geomagnetic Reference Field 1985. The user may opt against using an external contribution to the field or may select a number of options: Mead-Fairfield Quiet, M-F Disturbed, M-F Super Quiet, M-F Super Disturbed, Olson-Pfitzer No Tilt, or O-P Tilted. Calculations may be performed either at a point or along a field trace. The program prompts for the type of trace (up, down, north, or south), type of field model(s), the epoch, and the latitude, longitude, and altitude for the start of the trace or for the point. The output is the latitude, longitude, altitude and total field at the point or at various points along the trace. Three orthogonal components of the field (outward, south, and east) are also returned at each point. If a trace is requested, the equatorial value of $B$ and McIlwain's parameter $L$ are also provided if the equatorial region is crossed during the trace.

The Energetic Electron Models that are currently (November 1987) in EnvirONET are the AE6 electron model for the region $1.4 \leq \mathrm{L} \leq 2.2$ and $\mathrm{AE7}-\mathrm{Hi}$ for $2.2 \leq L \leq 8.25$. AE7-Hi consists of a number of two-component exponentials defined at the equator for a number of $L$ intervals. They are terminated at $7.5 \mathrm{MeV}$. The model calculation uses logarithmic interpolation in $E$ and $L$ and a $\sin ^{2} \lambda$ interpolation along the field line. The proton model used is AP6 for the intervals $1.2 \leq \mathrm{L} \leq 6.0$ and $0.1 \leq \mathrm{E} \leq 170 \mathrm{MeV}$. Tabular interpolation at the equator and along a field line are similar to those used in the electron calculation. Both unidirectional differential and integral flux are returned for the electrons. Only omnidirectional integral fluxes are returned for the protons. Values returned by these subroutines are within a factor of 2 to 3 of the values which AP8 and AE8 would predict. This accuracy is within the 
confidence limits of $A P 8$ and $A E 8$, and so can be used without reservation until the more comprehensive models are available.

\section{FUTURE PLANS}

Future plans include adding the following to EnvironET: downloading of all codes and models; incorporation of the AE8 electron and AP8 proton models; orbital integrations of fluxes; addition of the ORB and ORP codes from NSSDC. The orbital integrations will have limited orbital position and energy resolution in order to avoid having users overload the system by attempting to do detailed calculations. The intent will be that a user will be able to determine whether the energetic particle environment might be a problem or not. If it might be, the user then can download the appropriate codes and models and do more detailed calculations at his/her own facility.

More distant plans include the addition of dose calculations as a function of shielding and position in orbit and calculation of cosmic ray fluxes as a function of mass, energy, and position in orbit. 
The Aerospace Corporation functions as an "architect-engineer" for national security projects, speciallzing in advanced milltary space systems. Providing research support, the corporation's Labotatory Operations conducts experimental and theoretical investigations that focus on the application of scientific and technical advances to such systems. Vital to the success of these investigations is the technical staff's wide-ranging expertise and its ability to stay current with new developments. This expertise is enhanced by a research program aimed at dealing with the many problems assoctated with rapidly evolving space systems. Contributing their capabilities to the research effort are these individual laboratories:

Aerophysics Laboratory: Launch vehicle and reentry fluld mechanlcs, heat transfer and flight dynamics; chemical and electric propulsion, propellant chemistry, chemical dynamics, environmental chemistry, trace detection; spacecraft structural mechanics, contamination, thermal and structural control; high temperature thermomechanlcs, gas kinetics and radiation; $\mathrm{cw}$ and pulsed chemical and excimer laser development including chemical kinetics, spectroscopy, optical resonators, beam control, atmospheric propagation, laser effects and countermeasures.

Chemistry and Physics Laboratory: Atmospheric chemical reactions, atmospheric optics, light scattering, state-specific chemical reactions and radiative signatures of missile plumes, sensor out-of-field-of-view rejection, applfed laser spectroscopy, laser chemistry, laser optoelectronics, solar cell physics, battery electrochemistry, space vacuum and radiation effects on materials, lubrication and surface phenomena, thermionic emission, photosensitive materials and detectors, atomic frequency standards, and environmental cbemistry.

Computer Science Laboratory: Program verification, program translation, performance-sensitive system design, distributed architectures for spaceborne computers, fault-tolerant computer systems, artificial intelligence, microelectronics applications, communication protocols, and computer security.

Electronics Research Laboratory: Microelectronics, solid-state device physics, compound semiconductors, radiation hardening; electro-optics, quantum electronics, solid-state lasers, optical propagation and communications; microwave semiconductor devices, microwave/millimeter wave measurements, dlagnostics and radiometry, microwave/millimeter wave thermionic devices; atomic time and frequency standards; antennas, rf systems, electromagnetic propagation phenomena, space communication systems.

Materials Sciences Laboratory: Development of new materials: metals, alloys, ceramics, polymers and their composites, and new forms of carbon; nondestructive evaluation, component fallure analysis and reliablilty; fracture mechanics and stress corrosion; analysis and evaluation of materials at cryogenic and elevated temperatures as well as in space and enemy-induced environments.

Space Sctences Laboratory: Magnetospheric, auroral and cosmic ray physics, wave-particle interactions, magnetospheric plasma waves; atmospheric and lonospheric physics, density and composition of the upper atmosphere, remote sensing using atmospherlc radiation; solar physics, infrared astronomy, infrared signature analysis; effects of solar activity, magnetic storms and nuclear explosions on the earth's atmosphere, ionosphere and magnetosphere; effects of electromagnetic and particulate radiations on space systems; space instrumentation. 